\title{
Study on Sedimentary Records of Paleoclimate and Paleoenvironmental Evolution of the Dongsha Atoll of South China Sea in Recent 70 Thousand Years
}

\author{
Li tengfei ${ }^{1}$ \\ ${ }^{1}$ Key Laboratory of Environmental Change and Natural Disaster of Ministry of Education, Faculty of Geographical Science, Beijing \\ Normal University, Beijing 100875, People's Republic of China
}

\begin{abstract}
The Dongsha Atoll of South China Sea are located on the western reef terrace of Dongsha Atoll, where a large amount of terrigenous clastic materials and marine biomass are accumulated, which play an important role in the global material cycles. In recent years, the water level in this area has been on the decrease along with the frequent occurrence of floods, red tides, low-oxygen conditions and warmer waters as a result of worsening global ecology. In this paper, accelerated mass spectrometer (AMS) ${ }^{14 \mathrm{C}}$ was used to analyse the sediments in Dongsha Atoll of South China Sea, and studied the organic matter deposition in this area in the past 70,000 years combined with sediment grain size, geochemistry and other indicators, which revealed the influence of paleoclimate environment and climate change on the development of this area. The results showed that the environment and climate are essential to the distribution of particles, which can be divided into three layers from bottom to top, i.e., calcium-rich layer, organic matter layer and fine-grained sediment layer. $\mathrm{Al}_{2} \mathrm{O}_{3}, \mathrm{~K}_{2} \mathrm{O}, \mathrm{TFe}_{2} \mathrm{O}_{3}$ and $\mathrm{MgO}$ contribute $58.84 \%$ to the total variance, indicating that the composition plays a decisive role in the content of major elements in the region. Turbidity sediments have been widely distributed in different areas of the region since last glacial period, among which turbidity occurred most frequently in the period 200,000 years ago when the sea level was relatively low. This study provided a theoretical basis for the evolution of climate and environment in the South China Sea.
\end{abstract}

\section{Introduction}

Human activities have led to great changes in the global climate, bringing challenges such as population growth, environmental degradation, rising temperature and sharp decline in biodiversity that have gradually become issues of universal concern to people all over the world ${ }^{[1]}$. Only by fully understanding the activities related to global climate, environment, the formation, evolution and development of ecosystem as well as the relationship between man and nature, can we better guide efforts of environmental protection for sustainable development ${ }^{[2]}$. In the past two centuries, human activities have caused dramatic changes of the global temperature that fluctuates in the range from +5 to $-10^{\circ} \mathrm{C}$, which is not only a problem faced by researchers in this field, but also a major challenge to modern society ${ }^{[3]}$. In the 4.6 billion years of the earth's evolution, the Quaternary Period, the main period of climate fluctuation and human development, is of the greatest significance. Studying the climate and environmental changes in Quaternary is not only helpful for understanding the global climate, but also significant for predicting future climate changes ${ }^{[4]}$. As an important part of the global monsoon, the East Asian monsoon controls the seasonal wind, rainfall, runoff and land vegetation in eastern Asia. South China Sea is the largest marginal sea in the western Pacific Ocean, demonstrating typical climate and water-gas cycles as a result of the East Asian monsoon. The South China Sea is the major source of terrigenous clast. However, this area was widely exposed to the air during the last glacial low stand of sea level, when the terrigenous inputs far exceeded that during the last interglacial high sea level, which changed the supply pattern of terrigenous clastic in the South China Sea. Therefore, it is of great significance to study the changes of paleoclimate and environment in the South China Sea to understand paleooceanographic characteristics and the terrigenous inputs in the South China Sea.

Sediment dating is often used to study paleoclimate and environmental changes, which provides a chance to study past global changes on the time scale. Many scholars have reported studies on climate and environmental changes in sediments, among which Martin et al. (2017) used cluster analysis based on micro $\mathrm{X}$-ray fluorescence core scanning to observe the composition changes in sediment and linked them with changes of climate and environment ${ }^{[5]}$. Cho et al. (2018) studied the evolution of Huajinpo Lagoon by analysing the size of grain and the composition of at the layer of 
$11.0 \mathrm{~m}$ from the core (HJ02), and found that a large amount of rainfall in this area may be caused by Asian summer monsoon ${ }^{[6]}$. Liiv et al. (2019) used total organic carbon and total nitrogen of sediment core as an indicator of paleoclimate change in the eastern Baltic Sea during the late-glacial and early Holocene, which proved highly effective for investigating the past environmental changes of lakes and their watersheds ${ }^{[7]}$; Rodrigues et al. (2020) analysed the climate and environmental changes in Lusitania Basin via various underground sediments, which provided important insights for understanding the impacts of early climate events on terrestrial ecosystems ${ }^{[8]}$. While sediment is widely used in analysing and studying environment and climate, there are few sediment-based studies on the South China Sea. Because the South China Sea is of great significance to the development of China, this paper aims to study the evolution of paleoclimate and paleoenvironment in Dongsha Atoll of the South China Sea in the latest tens of thousands of years.

This paper used the accurate accelerated mass spectrometer (AMS) ${ }^{14 C}$, combined with analysis of sediment grain size, geochemistry and other indicators as well as the age framework based on carbonate strata and biostratigraphy to obtain the accurate age of sediment and explore changes in the productivity and the response of terrigenous inputs to paleoenvironment and climate evolution in the zone of upwelling in western South China Sea during the late Quaternary period. This study provides a basis for reconstructing the evolution pattern of East Asian summer monsoon.

\section{Method}

\subsection{Background information}

South China Sea, at the southern end of Asia, is located in the south of the mainland of China and close to Taiwan of China and the Philippine Islands in the low latitude area of $23^{\circ} 37^{\prime}$, as shown in Figure 1. It reaches Tropic of Cancer in the north, expands to the southern hemisphere across the equator in the south, with a latitude span of $26^{\circ} 47^{\prime}$ from the north to the south. The axis is about $3140 \mathrm{~km}$ long, with the short axis of NW (North by Southern) and a width of about $1250 \mathrm{~km}$. It covers an area of $350 \times 104 \mathrm{~km} 2$, with an average water depth of more than $1000-1100 \mathrm{~m}$. The basin in the middle of the area can reach up to $4200 \mathrm{~m}$ in depth, with the continental shelf and island shelf accounting for about $48.15 \%$ of the total coverage of the South China Sea. The average water depth in the deep water is about $4700 \mathrm{~m}$, of which $80 \%$ consists of terrigenous clastic transported by surrounding rivers, while the remaining $20 \%$ is made up of biocarbonate, silicate and volcanic ash sediments ${ }^{[9]}$.

The Dongsha Atoll consists of a group of islands at the northern end of the South China Sea, which is close to the mainland and boasts the least number of islands and reefs. It is also one of the earliest developed islands in the South China Sea ${ }^{[10]}$. This paper studied the slopes in the northeast part of The Dongsha Atoll. The special geographical location helps form the sophisticated structure and sedimentary activities in this area, and its superior geological conditions are conducive to hydrate accumulation, as evidenced by the high density of methane at the top layer of sediment and obvious methane leakage on the seabed. This area also has more active cold springs and ancient cold springs on the seabed that other areas in the South China Sea.

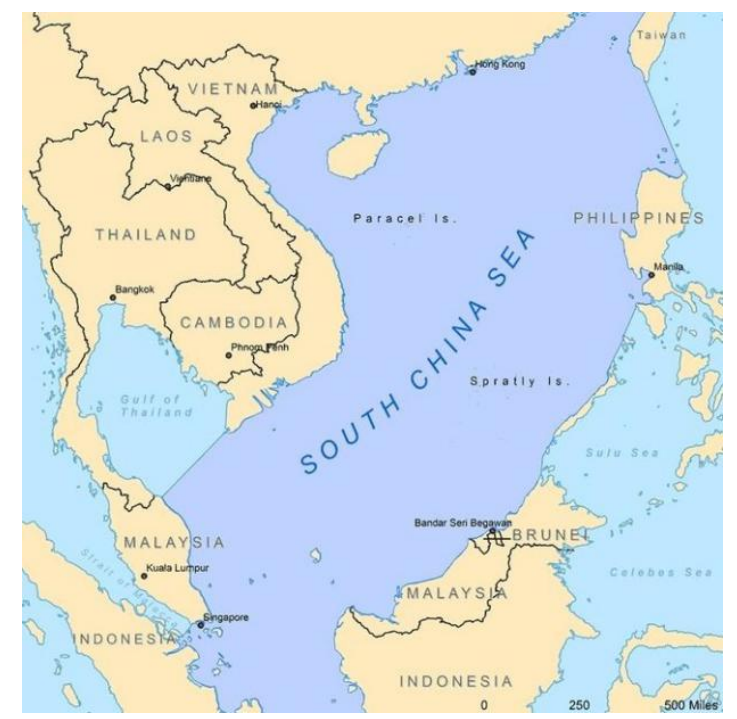

Figure 1 Distribution of South China Sea and Neighbouring Countries

\subsection{Sample collection}

The columnar samples were collected from the slopes of Dongsha Atoll in the South China Sea (Figure 1), with a water depth of $1026 \mathrm{~m}$ and a length of $1228 \mathrm{~cm}$. According to the results of core observation and indoor grain size analysis, the columnar samples were characterized by complex and changeable lithology, with a coarse texture composed of gray-green silty clay mixed with thin silty sand and foraminiferal silty sand. The layer at $405-1228 \mathrm{~cm}$ was relatively simple in lithology, with fine sediment composed of gray silty clay mixed with thin layers of silty sand. The sediment had uniform lithology without much biological disturbance. Take $40 \mathrm{~g}$ dry sediment sample, place the sample in a beaker, soak it in tap water for 1-2 days without any chemical dispersant until it was completely dispersed, and wash it through a 250-mesh copper sieve (aperture: $0.063 \mathrm{~mm}$ ), and ensure that each sample was washed clean to avoid pollution. Leave the sample on the sieve to dry and weigh at $60^{\circ} \mathrm{C}$, and calculate the composition of the crude sediment. The sample was scanned and measured by X-ray fluorescence (XRF) with a resolution of $1 \mathrm{~cm}$, and sampled at the interval of $1 \mathrm{~cm}$. 


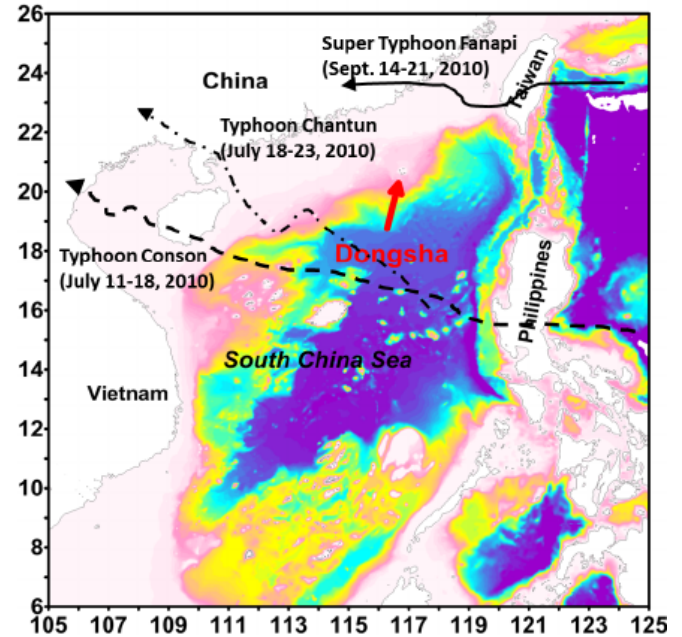

Figure 2 Location of Sampling in Dongsha Atoll of South China Sea

\subsection{Sediment analysis}

Twelve samples with different depths were selected for dating, including 11 foraminifera and 1 plant fragment. Specifically, two species of foraminifera, namely Globigerinoides ruber and Globigerinoides sacculifer, were selected for analysis under the microscope, as shown in Figure 3. The foraminifera were collected from the layer of $0-1 \mathrm{~cm}, 37-38 \mathrm{~cm}, 77-78 \mathrm{~cm}, 119-120 \mathrm{~cm}$, $177-178 \mathrm{~cm}, 239-240 \mathrm{~cm}, 377-378 \mathrm{~cm}, 447-448 \mathrm{~cm}, 498-$ $499 \mathrm{~cm}$ and $549 \mathrm{~cm}$ from top to bottom respectively. Samples were sent to Beta Analytic (a laboratory based in the US) for dating via AMS ${ }^{14 C}$. Traditional foraminiferal and plant debris samples were handled by MARINE 13 and INTCAL 13 for $2 \sigma$ correction.

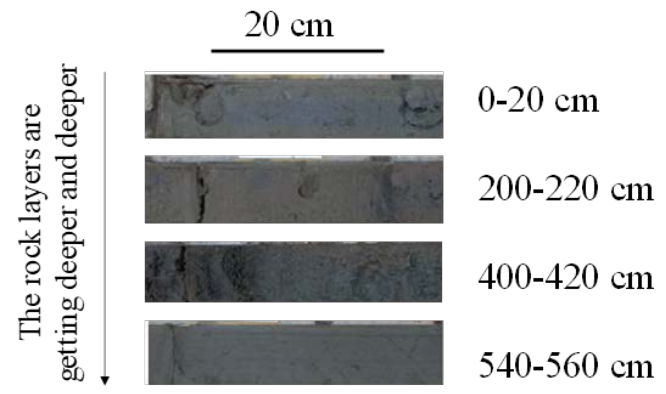

Figure 3 Collection of Analysis of Some Samples

\subsection{Elemental analysis}

The elemental analysis was conducted using X-ray fluorescence spectrum. Firstly, take $1.2 \mathrm{~g}$ sample which was burned at $920^{\circ} \mathrm{C}$ for $4 \mathrm{~h}$ to measure ignition loss of the sample. Take $5.0 \mathrm{~g}$ flux and $0.5 \mathrm{~g}$ sample weighed by electronic scales, stir and mix the weighed reagent and the sample evenly with a glass rod before pouring them into platinum crucible, where 6 drops of release agent were added to increase surface tension. Put the platinum crucible in a melting machine, heat it at $1200^{\circ} \mathrm{C}$ for $5 \mathrm{~min}$ to melt the sample and cool it for $3 \mathrm{~min}$ before taking out the glass melt from the platinum crucible for labelling in the sample bag. Then, test it with the X-ray fluorescence spectrometer. One control group was added to every 20 samples, while one blank sample and four standard samples were included in each batch of tested samples. The test results were corrected based on the blank sample and standard samples.

\subsection{Granularity test}

When the rock core was brought back to the laboratory, cut the core from the midline position, and then take samples required for testing by section. A sample with a thickness of $1 \mathrm{~cm}$ was taken every $2 \mathrm{~cm}$ for particle size test. In the first step, the sample was dried at $80^{\circ} \mathrm{C}$ before $1 \mathrm{~g}$ sample was soaked in distilled water containing 0.05 $\mathrm{N}$ sodium phosphite for $24 \mathrm{~h}$. Then, it was treated for 15 min under ultrasonic condition. All samples were tested by Malvin 2000G laser particle analyser, with a test range of $0.02-2000 \mu \mathrm{m}$.

\section{Result and Discussion}

\subsection{Distribution of particle size of sample sediment}

The distribution of grain size of the samples is shown in Figure 4, where Layer A, B and E in this area is characterized by single peak and narrow peak, while Layer $\mathrm{C}$ and $\mathrm{D}$ feature much more coarse sediment, with some samples being distributed in double peaks and wide peaks. The grain size of Layer D shows a sudden increase, with a sharp rise in the sand content. Layer A and $\mathrm{E}$ demonstrates few changes, while Layer $\mathrm{B}$ and $\mathrm{C}$ show slightly greater changes. Layer $\mathrm{D}$, in particular, consists of silty, the bottom of which could be dated back to 70,000 years ago after correction. The above results show that the layer may consist of abnormal sediments that were not disturbed by subversion, which can be used to trace the regional climate and environmental changes in the Dongsha Atoll of South China Sea in the past 70,000 years. 

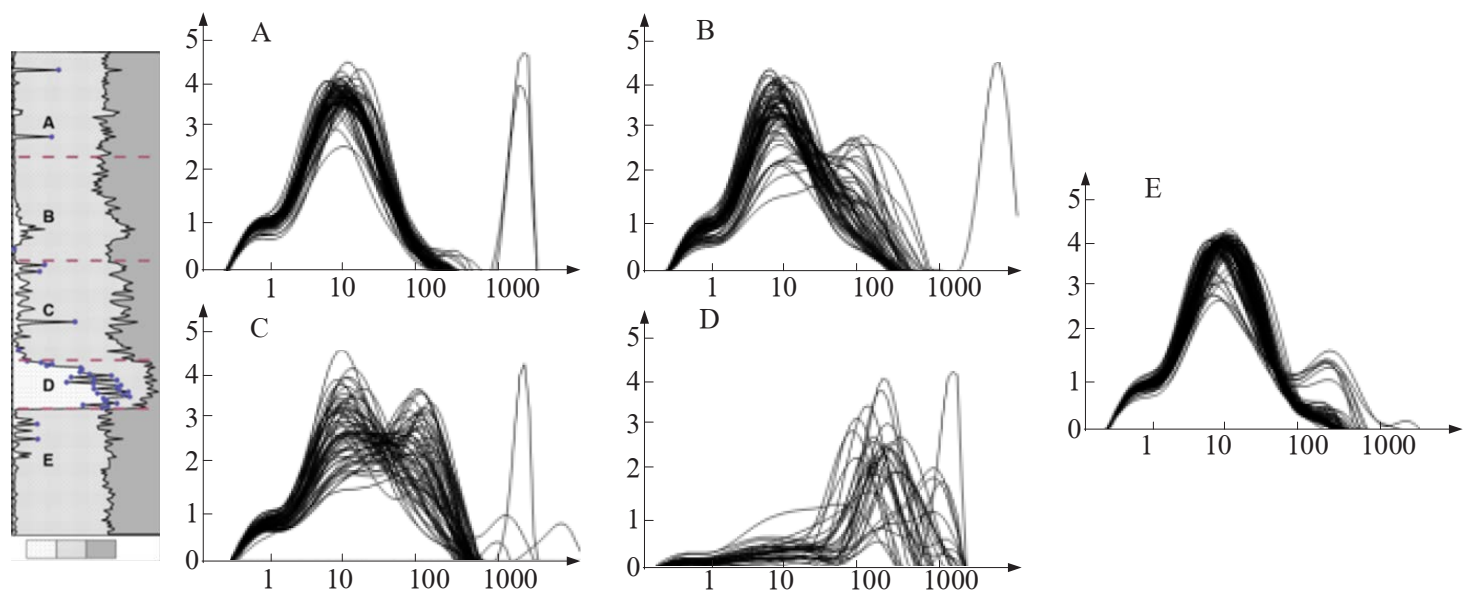

\subsection{Characteristic analysis of sample sediment}

The sediment characteristics of the sample are shown in Figure 5, which included a sand layer with a thickness of $60 \mathrm{~cm}$ at the depth of 380-440 cm consisting of coarse grains like foraminiferal shells and plant debris that can be seen with naked eyes. The grain size of this layer gradually narrows from the bottom to the top, with discordant contact between the bottom and the lower layers. Compared with other layers, there are more foraminifera at the bottom layer and fewer foraminifera at the top, which is smaller in volume and higher in plant debris content. The above characteristics basically

A

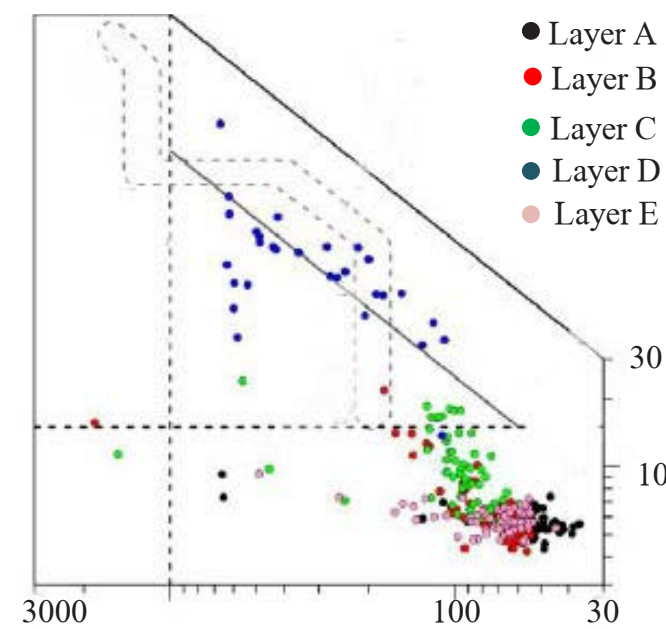

$\mathrm{C}$

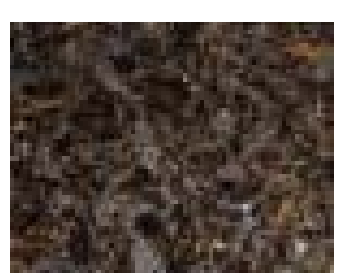

$410 \mathrm{~cm}$

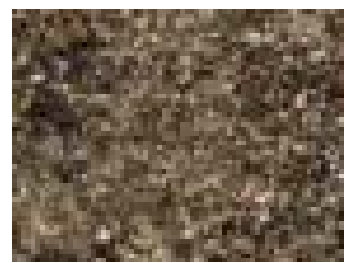

Figure. 5 Characteristics conforms to the pattern of normal graded bed sequence in the typical turbidite sequence. The results of macroscopic observation, sediment granularity and TOC test show that the layer can be further divided into three layers from bottom to top: calcium-rich, organic matter and fine-grained sediment layer. Both the deep sea plain in the west of South China Sea and the Dongsha Atoll in the north are rich in calcium carbonate caused by turbidity transport. Meanwhile, plant debris was found in turbidity sediments on the slope in the north. However, sediments mixed with calcareous components and plant debris have not been found yet.

\section{B}
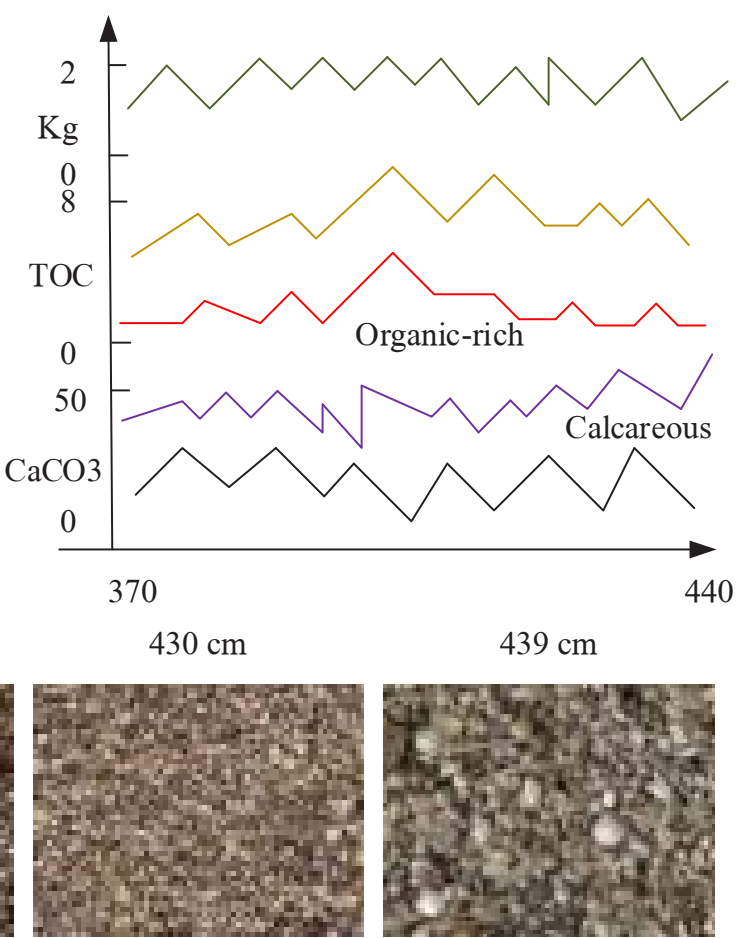

of Sample Sediment

indicating the decisive role of the element in the composition of sediment in this region. Elements with a higher load coefficient of PC1 include $\mathrm{Al}_{2} \mathrm{O}_{3}, \mathrm{~K}_{2} \mathrm{O}$, $\mathrm{TFe}_{2} \mathrm{O}_{3}$ and $\mathrm{MgO}$. The four elements of $\mathrm{Al}_{2} \mathrm{O}_{3}, \mathrm{~K}_{2} \mathrm{O}$,
As shown in Figure 6 and Table 1, the principal element 1 (PC1) contributed to $58.84 \%$ of the total variance, 
$\mathrm{TFe}_{2} \mathrm{O}_{3}$ and $\mathrm{MgO}$ evolved almost synchronously in a pattern almost completely opposite to that of $\mathrm{SiO}_{2}$. Generally, SiO2 mainly exists in quartz, followed by silicate such as feldspar and clay. The $\mathrm{Si}$ of silicate combines with oxygen to provide anions, while $\mathrm{Al}, \mathrm{K}, \mathrm{Fe}$

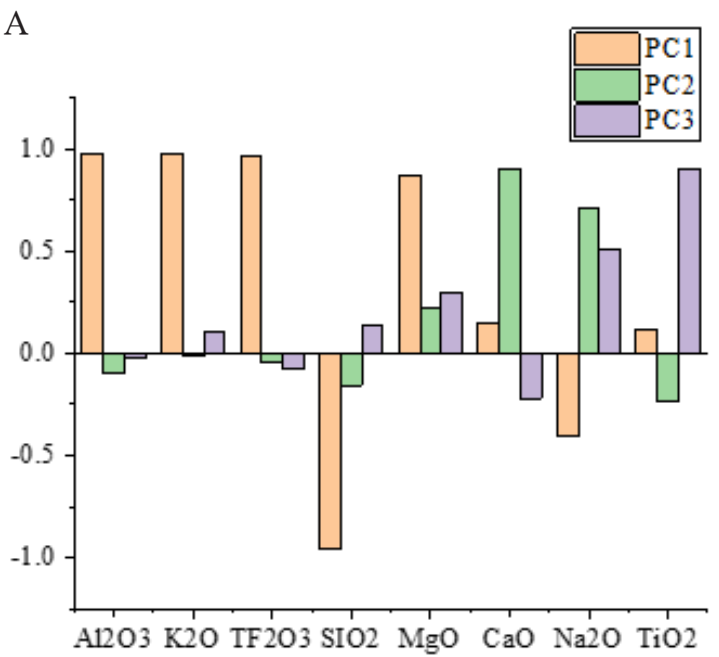

and $\mathrm{Mg}$ offer cations. Therefore, there is no so-called "dilution" between them. Tests on different types of clay show that the content of $\mathrm{Si}$ in clay is $50 \%$ lower than other minerals.

B

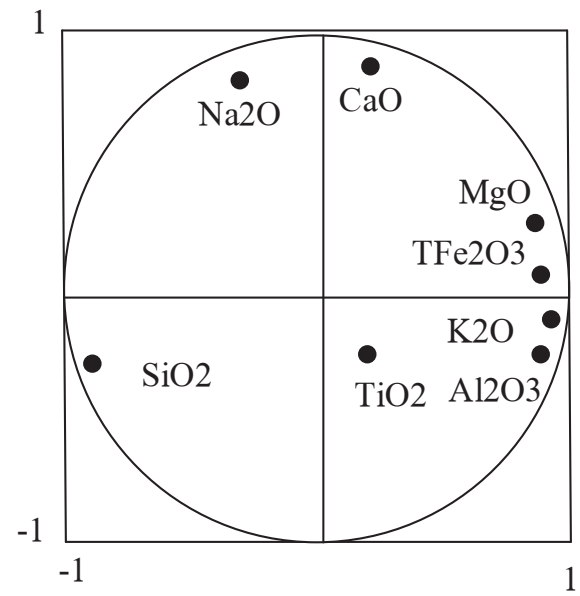

Figure. 6 Analysis of Major Elements in Sediment

Table. 1 Proportions of Major Elements in Sediment

\begin{tabular}{|c|c|c|c|}
\hline & PC1 & PC2 & PC3 \\
\hline Variance(\%) & 58.84 & 18.15 & 15.52 \\
\hline $\begin{array}{c}\text { Cumulative } \\
\text { variance (\%) }\end{array}$ & 58.84 & 76.98 & 92.51 \\
\hline
\end{tabular}

\subsection{Response of sedimentation to paleoclimate and environment}

Figure 6 shows the paleoclimate and environmental changes recorded by sediments. From the figure, it is known that turbidity sediments are widely distributed in different regions since the last glacial period. A large number of turbidity currents appeared in the northern part of the South China Sea, which may be related to drastic differences of the terrains and slopes at the depth of $1000-4000 \mathrm{~m}$, the large amount of sediment transported by rivers, deep water intrusion from the western Pacific Ocean, cold spring activities and the development of waterways in the continental slope. Change in sea level was the main factor causing turbidity current in the South China Sea, which occurred most frequently in MIS 2 Period when the sea level was relatively low. There was not as much turbidity current in MIS 3 and MIS 4 Period. During the sub-glacial period, there was a decrease in the sea level all over the world. The Dongsha Atoll in the South China Sea was most likely to be formed in the period of low sea level and short sediment transport distance.

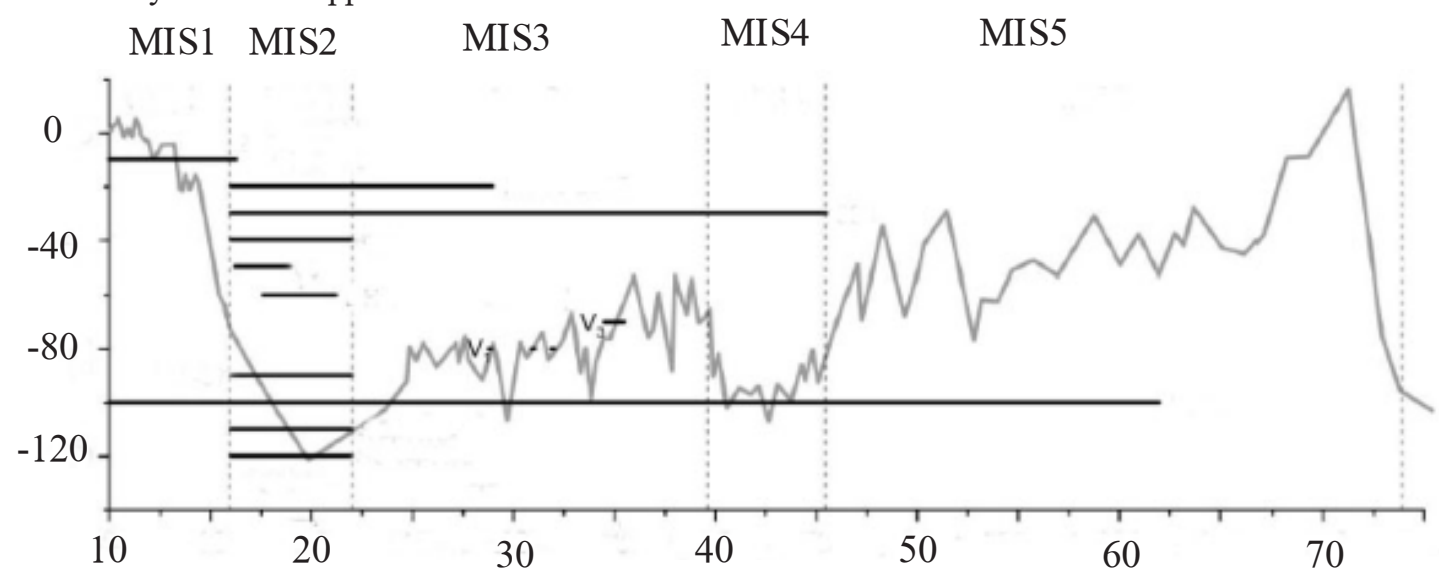

Figure. 7 Paleoclimate and Climate Changes Recorded by Sediment

\section{Conclusion}

This paper examined all the main indicators of organic matter in marine sediments of the South China Sea in the latest 70,000 years, and retrieved the records of paleoclimate environment and climate changes in this period. The reconstructed paleoclimatic conditions and changes in marine primary productivity were verified based on literature records and satellite data. Based on 
this, the related parameters were applied to explain the evolution of paleoclimate and environment in this area since Holocene. The sediment formed in 70,000 years in Dongsha Atoll of South China Sea was a result of changes in sea level and climate, while the formation of turbidity current was attributed to low sea level and favourable topography. The grain size of normal sediments was close to clay, fine sand, medium silt or between coarse silt and fine sand. Sea level change was the main factor causing turbidity current in the South China Sea, which occurred most frequently 200,000 years ago when the sea level was relatively low, which decreased 400,000 years ago and 450,000 years ago. Although this paper used sediments to analyse the climate and environmental changes in this area in the latest 700,000 years, there are also drawbacks in this paper due to the limitation of technology, including: first, this paper did not use other detection methods, including geochemical and magnetic field analysis, which greatly limited the range and scope of climate and environmental analysis in this area; second, this paper did not analyse the overall climate and environmental changes from perspectives like atmospheric movement of the entire Pacific Ocean. In the future, we will conduct in-depth analysis in these aspects, thus providing practical references for the study of climate changes in East Asia.

\section{Author information:}

Li Tengfei (1988-), Beijing Normal University, male, born in Jining, Shandong Province, Ph.D., majoring in geography and environment of arid areas.

\section{References}

1. Wang Y, Chan A, Lau GNC, Li Q, Yang Y, Yim SHL. Effects of urbanization and global climate change on regional climate in the Pearl River Delta and thermal comfort implications. International Journal of Climatology. 2019, 39(6), pp. 2984-2997

2. Shrivastava M, Cappa CD, Fan J, Goldstein AH, Guenther AB, Jimenez JL, Kuang C, Laskin A, Martin ST, Ng NL. Recent advances in understanding secondary organic aerosol: Implications for global climate forcing. Reviews of Geophysics. 2017, 55(2), pp. 509-559.3.Engelbrecht CJ,

3. Engelbrecht FA. Shifts in Köppen-Geiger climate zones over southern Africa in relation to key global temperature goals. Theoretical and applied climatology. 2016, 123(1-2), pp. 247-261.

4. Coppock RL, Cole M, Lindeque PK, Queirós AM, Galloway TS. A small-scale, portable method for extracting microplastics from marine sediments. Environmental Pollution. 2017, 230, pp. 829-837.

5. Martin P C, Tjallingii R, Bloemsma M, Brauer A. Varved sediment responses to early Holocene climate and environmental changes in Lake Meerfelder Maar (Germany) obtained from multivariate analyses of micro X-ray fluorescence core scanning data. Journal of Quaternary Science. 2017, 32(3), pp. 427-436.

6. Cho A, Cheong D, Kim JC, Yang DY, Lee JY, Kashima K, Katsuki K. Holocene climate and environmental changes inferred from sediment characteristics and diatom assemblages in a core from Hwajinpo Lagoon, Korea. Journal of Paleolimnology. 2018, 60(4), pp. 553-570.

7. Liiv M, Alliksaar T, Amon L, Freiberg R, Heinsalu A, Reitalu T, Saarse L, Seppä H, Stivrins N, Tõnno I. Late glacial and early Holocene climate and environmental changes in the eastern Baltic area inferred from sediment $\mathrm{C} / \mathrm{N}$ ratio. Journal of Paleolimnology. 2019, 61(1), pp. 1-16.

8. Rodrigues B, Duarte LV, Silva RL, Mendonça Filho JG. Sedimentary organic matter and early Toarcian environmental changes in the Lusitanian Basin (Portugal). Palaeogeography, Palaeoclimatology, Palaeoecology. 2020, pp. 109781-109790.

9. Sun R, Yu J, Liao Y, Chen J, Wu Z, Mai B. Geographical distribution and risk assessment of dichlorodiphenyltrichloroethane and its metabolites in Perna viridis mussels from the northern coast of the South China Sea. Marine Pollution Bulletin. 2020, 151, pp. 110819-110825.

10. Tkachenko KS, Soong K. Dongsha Atoll: A potential thermal refuge for reef-building corals in the South China Sea. Marine environmental research. 2017, 127, pp. 112-125. 